\title{
The Psychopath as an Irrational Agent: A Canadian Criminal Law Perspective by Kevin Moustapha
}

\section{Kevin Moustapha*}

\section{LLD Candidate and lecturer at the University in Montreal (Faculty of law), Canada}

${ }^{*}$ Corresponding author: Kevin Moustapha, LLD Candidate and lecturer at the University in Montreal (Faculty of law), Canada, E-mail: kevin.moustapha@umontreal.ca

Citation: Kevin Moustapha (2017) The psychopath as an irrational agent: a Canadian criminal law perspective by Kevin Moustapha. J Forensic Sci Criminol 5(2): 204

Received Date: March 10, 2017 Accepted Date: April 20, 2017 Published Date: April 22, 2017

\begin{abstract}
The purpose of this study is to look at the capacity of psychopaths to act in a rational manner within the meaning of section 16 of the Canadian Criminal Code. We therefore focus on certain neuroscientific studies in order to see whether they can inform us about the disorders that psychopaths suffer from, and whether those disorders could have an impact on their ability to act rationally. If they do, then psychopathy could be an ailment that triggers the section 16 defence of not criminally responsible owing to a mental disorder and also the implications of the Supreme Court of Canada decision in Bouchard-Lebrun.
\end{abstract}

Keywords: Forensic Psychopathy, neurosciences, rationality, insanity defence, Canada

\section{Introduction}

Thanks to the advanced analyses and diagnoses that science has provided us with in recent years, more and more questions are being raised regarding the precise nature of psychopathy. Initially considered to be a personality disorder in international classifications, psychopathy is now a major subject of scientific discussion on brain dysfunctions. In the field of neuroscience, for example, the studies by Kent Khiel, R.J.R Blair and Adrien Raine have made it possible to corroborate a number of symptoms linked with psychopathy. According to them, the dysfunction of certain areas of the brain in psychopathic individuals could be the direct origin of their antisocial behaviour.

Among those studying the Canadian insanity defence, this theory has sparked interest in that it could provide a partial explanation of why psychopaths sometimes behave irrationally. Nonetheless, although the plenitude of these various studies allows us to glean increasingly relevant information about the nature of psychopathy, taken as a whole, these medical and neuroscientific theories are insufficient to establish with certainty that dysfunction in certain regions of the human brain inexorably leads the individual to commit criminal offences. However, developments in medical science, coupled with the valuable teachings of neuroscience, open the way to a debate on the possible application of the Canadian insanity defence to psychopathy. Section 16 of the Criminal Code excuses individuals who are unable to understand their environment and interact with others in a rational manner. In Canadian criminal law, the inability to make a rational choice can flow from a whole range of mental disorders. As the justices in BouchardLebrun stated, criminal law presumes that every person is independent and rational, and that his or her acts and omissions incur liability [1]. In this regard, we think that psychopathy is a disorder that could overturn that presumption, referred to in BouchardLebrun. We view emotional and volitional problems as responsible for mental disturbances that deprive a psychopath of the ability to assess, rationally, what he or she is doing. Psychopaths' clear failures on the moral level (circuit of emotions) and the difficulties they may encounter when making decisions (volition) lead them perceive a bad action as good or justifiable. In order to explore this, we will begin by analysing the link between the notions of psychopathy and irrationality (I). Next, we will see that, thanks in particular to the contributions of neuroscience, it is now possible to state that psychopaths are unable to act rationally within the meaning of Canadian criminal law. Nonetheless, we have to ask whether considering them not criminally responsible might not be such a good idea (II).

\section{the link between the notions of psychopathy and irrationality}

\section{A) Rationality, a fuzzy, even elusive concept}

In the strict sense of the term, rationality refers to the nature of what is rational [2]. The concept of rationality comes into play "every time we view human behaviour from the angle of action, more specifically, action that obeys reasons" [3]. Above all, the 
principal characteristic of rationality is that it confers a form of intelligibility and predictability to all of human behaviour ${ }^{1}$. Finally, rationality seems to have an explanatory function". The term "rational" provides us with further information. From the Latin rationalis, the term "rational" refers to all that is specific to reason [4]. This therefore implies that, to be rational, an action or form of behaviour must appear logical, reasonable and in accordance with good sense [4]. While making a rational choice often refers to economic, or even political or sociological, reasons [5], we have to admit that rational choice theory has gradually been exported to more distant lands, such as criminology [6] and criminal law [7]. Beyond academic studies of the notion of rationality, it is useful to note that it is difficult to unravel this concept with precision, no matter what the discipline in the human and social sciences [8]. Law, and more specifically criminal law, is no exception to this because neither case law nor doctrine seems to provide a definition of rationality in the legal sense of the term. Stephen J. Morse also refers to these difficulties when he tried to decipher the concepts of rationality and irrationality: "Rationality and irrationality are continuum concepts. The degree of irrationality required [to conclude that an agent is not responsible] might vary from context to context. For example, the amount of irrationality that would permit a finding of incompetence to contract need not be the same as the amount necessary to avoid criminal liability [9]. These highly useful comments by Morse confirm that the concepts of rationality and irrationality remain fuzzy and almost elusive. However, it is above all the very relative dimension of these notions that stands out. Depending on the area of law in question, these terms have very different meanings. From this observation thus flows the fact that the notions of rationality and irrationality are normative, certainly, but above all contingent. This idea can also be found in Morse's writings: If human beings were not creatures who could understand and follow the rules of their society, who could not be guided by reasons, the law and all other systems, such as morality, that regulate conduct by reasons and rules would be powerless to affect human action. Rule followers must be creatures who are capable of properly using the rules as premises in practical reasoning. It follows that a legally responsible agent is a person who is so capable according to some contingent, normative notion of both rationality itself and how much capability is required. For example, legal responsibility might require the capacity to understand the reason for an applicable rule, as well as the rule's narrow behaviour command. These are matters of moral, political, and, ultimately, legal judgment, about which reasonable people can and do differ. There is no uncontroversial definition of rationality or of what kind and how much is required for responsibility. Finally, these difficulties resulting from the definition of the concept of rationality in criminal law, and more specifically with respect to the insanity defence, give judges some latitude since the concept is flexible. The flexibility seems to be a real advantage for psychopathic individuals, who have rarely been associated with any form of irrationality in criminal law, despite the seriousness but especially the impact of their disorders with regard to their antisocial behaviour. This observation has to be taken into account in the structure of our reflection since we hold that neuroscience can explain in part why psychopaths suffer from a form of irrationality, and that this can be used as a basis for showing that psychopaths meet the second criterion of section 16 of the Criminal Code. The dysfunction of areas linked with emotions has a significant effect on psychopaths' ability to distinguish well from bad, and thereby make rational choices in accordance with that distinction. As philosopher Samuel Lepine says with exemplary clarity, "psychopaths certainly may wield the concepts of good and bad, but those concepts are devoid of their evaluative and prescriptive value in their eyes. In other words, psychopaths seem to be indifferent with respect to moral rules very simply because they do not consider that things are really morally good or bad, but only that they are considered good or bad by other people". It seems that the conflict between reason and emotions when determining volition has now become anachronistic. The anachronism flows obviously from recent contributions by neuroscience, which, instead of placing reason and emotions in opposition, associates them in moral judgment, as well as in decision making. Rather than seeing reason and emotions as enemies in analysis of psychopathy, some neuroscientists make them allies in order to show that they are essential and above all complementary in an individual's decision-making process.

Today, we can also assess the impact of neuroscientific disciplines against the measure of studies on the complementarity between reason and emotions, and their impact on the moral judgment indispensable in an individual's decision-making process. Indeed, it is very interesting to note that most neuroscientists studying the issue base their work on psychopathic dysfunctions to illustrate the very essence of their respective reflections [10]. Can we consider that it is irrational for an individual to be amoral? Finally, is the principle of rationality a function of our ability to use our reason or of our ability to use our emotions? In order to best develop the concept of irrationality in psychopathy, we need to identify the principal questions that have to be raised to understand how reason and emotion are hinged together, and especially whether an individual's inability to analyse his or her environment on the moral level flows exclusively from an emotional deficit, or is instead related to reasoning disorders.

\section{B) The neuroscientific approach to psychopaths' rationality: between reason and emotions}

One of the first neuroscientists to describe the brain as a sophisticated device indispensable for an individual to have free choice is Michael Gazzaniga. He sees it as an instrument that makes it possible for an individual to interact with his or her environment so as to be able to learn how to determine his or her own way of reacting, and as an evolving system for making decisions [11]. However, it is Antonio Damasio who places the faculty of reason at the centre of biological regulation mechanisms involving,

\footnotetext{
${ }^{1}$ Philippe Mongin says that three positive functions can be attributed to the concept of rationality. The concept "would express and establish the intelligibility, from a certain angle, of observed behaviour. It defines a range of interpretations among others that are conceivable, namely that of rational interpretation. The intelligibility of the behaviour is the minimum result that can be anticipated from successful application. According to a stronger, more hypothetical thesis, the principle would express and establish the not only interpretable, but predictable nature of certain forms of behaviour." [Our translation.]

${ }^{2}$ Mongin P notes that it is indeed « in this field that the principle of rationality meets most specifically the methodology of social sciences ». [Our translation.]
} 
notably, emotions. According to Damasio, our moral judgment, and general, social and moral decision-making occurs thanks to the collaboration of different levels of our brain [12]. He replaces emotion at the centre of the individual's decision process, and makes it the perfect ally of reason.

Thus, Damasio highlights the fact that emotion plays a role in reason and assists in the reasoning process, instead of necessarily disturbing it, as was supposed by a certain Cartesian line of thought, of which one of the best examples is none other than René Descartes himself. Damasio's line of thought reminds us once again to what point emotions are essential in an individual's adaptive process. His research is all the more remarkable in that it makes it possible to establish the foundations for an analysis of psychopathy from the point of view of an allegedly unbreakable link between reason and emotions. In his work, Descartes' Error, he bases his arguments on the concrete example of a nineteenth-century psychopath named Phineas Gage. In order to fully understand the structure of Damasio's thought and see how it is linked with psychopathic disorders, we need to take a short look at this case. Phineas Gage, foreman of a company specializing in building railroads and respected by his peers for his abilities, skillfulness and good manners, was the victim of a terrible work accident. Following an error, a 6-kilo, 3 centimetre thick, 110-centimetre long iron bar was blown right through his head. Against all expectations, Gage survived his injuries. However, the most important aspect of the event is to be seen in regard to the extraordinary change in personality that the man subsequently experienced. His behaviour changed radically. Whereas he used to be jovial and peaceful, he became irritable and violent to such a point that his employer had to let him go [13]. At the time, science did not have the tools necessary to diagnose an antisocial personality disorder, or even a psychopathic disorder. It was thus only a century and a half later, under the influence of researchers such as Damasio, that neuroscientists, aided by the formidable technological progress in tools for observing the human brain, were able to locate the damaged brain areas that were at the origin of Gage's change in personality and his lack of morality. Damasio uses the theory of somatic markers to explain Gage's new behaviour [12]. The somatic marker hypothesis entails that emotions participate in reason and that they can assist the reasoning process, instead of hindering it. His explanation of this idea is very clear: Because the feeling is about the body, I gave the phenomenon the technical term somatic state ("soma" is Greek for body); and because it "marks" an image, I called it a marker. Note again that I use somatic in the most general sense (that which pertains to the body) and I include both visceral and nonvisceral sensation when I refer to somatic markers. What does the somatic marker achieve? It forces attention on the negative outcome to which a given action may lead, and functions as an automated alarm signal which says: Beware of danger ahead if you choose the option which leads to this outcome. The signal may lead you to reject, immediately the negative course of action and thus make you choose among other alternatives. The automated signal protects you against future losses, without further ado, and then allows you to choose from among fewer alternatives. There is still room for using a cost/benefit analysis and proper deductive compe $\rightarrow$ tence, but only the automated step drastically reduces the number of options. Somatic markers may not be sufficient for nor $\neg$ mal human decision-making since a subsequent process of reason $\neg$ ing and nal selection will still take place in many though not all instances. Somatic markers probably increase the accuracy and e ciency of the decision process. Their absence reduces them [14]. Thus, when the circuit of emotions (of the brain) is affected, as in the case of Phineas Gage, the entire decision process is affected. Given that emotion and reason work together in establishing moral judgment, an individual who suffers emotional dysfunctions may begin to make inconsistent decisions that will gradually take him or her down the path of irrationality. A series of antisocial forms of behaviour adopted by Gage after his accident provides a perfect illustration of this idea, thereby confirming the idea that emotional problems resulting from brain problems can foster antisocial behaviour. Moreover, it is important to note that in the most extreme cases, such as that of Gage, the individual's behaviour is not only antisocial but also completely irrational. This is what Damasio very rightly reminds us when discussing psychopathic disorder; developmental sociopaths or psychopaths are well known to all of us from the daily news. They steal, they rape, they kill, and they lie. They are often smart. The threshold at which their emotions kick in, when they do is so high that they appear unflappable, and are, from their self-reports, unfeeling and uncaring. They are the very picture of the cool head we were told to keep in order to do the right thing. In cold blood and to everybody's obvious disadvantage including their own, sociopaths often repeat their crimes. They are in fact yet another example of a pathological state in which a decline in rationality is accompanied by diminution or absence of feeling. It is certainly possible that developmental sociopathy arises from dysfunction within the same overall system which was impaired in Gage, at cortical or subcortical level. But rather than resulting from blunt macroscopic damage occurring in adulthood, however, the impair $\neg$ ment of developmental sociopaths would come from abnormal circuitry and abnormal chemical signaling and begin early in develᄀopment. Psychopathy, which is translated precisely by the dysfunction of an individual's circuit of emotions, therefore seems to be perfectly consistent with the canons of the theory of somatic markers developed by Damasio. Indeed, with respect to the theory of somatic markers, how can we say for certain that a psychopath has the ability to interact with his or her environment in a rational manner when his or her emotional faculties are defective? Psychopathy is the perfect disorder to support Damasio's research because it is one of the only disorders that are described mainly by a major failure at the level of emotions. If our system of reasoning is efficient only because it is an extension of our emotional system, as some neuroscientists say, then it seems inconceivable from a scientific point of view to consider a psychopath as a rational being. Since brain imaging shows that a psychopath absolutely does not have the ability to feel the emotions that he or she expresses (although there seems to be some compensation of affective failures through mimetism) [15], it seems difficult to say with certainty that psychopaths' decision-making process is not deficient. Not only is emotion the perfect complement of reason when establishing a moral judgment, but it is also one of an individual's essential mechanisms for making rational choices. Psychopathic disorders are, in the end, only a striking example of the fact that emotions play a role in making all individuals into rational beings, able to interact with 
their environment. Deep analysis of a psychopath's rationality leads to questioning of the positions traditionally adopted in philosophy. Confined to analysis flowing from the opposition between rationalism and sentimentalism, the study of rational behaviour now takes the royal road drawn by neuroscience. Contrary to rationalist affirmations, to be rational does not necessarily mean cutting oneself off from one's emotions. In contradiction with what sentimentalists might say, emotions are not the only things that come into play in the establishment of moral judgments: they must be associated with reason. Moral judgment and all the mechanisms at the origin of an individual's decision process thus follow from this association between reason and the emotions. Neuroscientific studies of rational behaviour have made it possible for us to conceptualize the principle of a psychopath's irrationality and to see what the implications in law could be with regard to section 16 of the Criminal Code and the jurisprudence established by Bouchard-Lebrun.

\section{The psychopath's inability to behave rationally}

\section{A) Possible application of the Canadian insanity defence to psychopathic disorders}

In line with our analysis above, emotional disorders have significant influence on the immorality of psychopaths. However, to an even stronger degree, such emotional disorders prevent psychopaths from behaving in a rational manner. Regarding the problems related in particular to brain dysfunctions, we think that psychopaths are unable to behave rationally. This hypothesis, though far from being unanimously accepted, has nonetheless been suggested a number of times by some authors, who draw a parallel between psychopathy and irrationality. They include Paul Litton and Heidi Maibom, who have studied in detail the difficulties that psychopaths encounter when trying to behave rationally. These authors base all of their argumentation on the famous inability of the psychopath to behave in a rational manner. According to them, this incapacity is what prevents psychopaths from assessing their actions in relation to public standards set by the state. In order to analyse all of the components of a psychopath's irrationality, we will focus on the various arguments developed by these two authors. To begin with, according to Professor Litton, psychopathic disorders cannot be summarized as simply a deficiency on the moral level. According to him, psychopaths' actions lack consistency, which would explain in part their inability to behave rationally. That inability allegedly flows from the fact that psychopaths cannot evaluate, decipher or analyse signs in their environment accurately. It is not merely that the psychopath has not internalized any moral standards; he has a weakened capacity for possessing any kind of evaluative standards, and that weakened capacity is related to signs of irrationality [...] Individuals with psychopathy may not exhibit the kind of disordered thinking prevalent in psychoses, but agents can be irrational in other ways. Young children are not responsible due to their lack of rational powers, and in many ways, persons with psychopathy are similar [16].

Traditionally, irrational actions are associated with afflictions, such as psychotic disorders, dementia or psychoses caused by intoxicating substances. Yet, like Paul Litton, we think that psychopathic individuals demonstrate a form of irrationality. According to him, it is above all the absence of morality that determines the irrational actions that psychopaths perform. In the end, what we draw from his arguments is that it is because psychopaths are totally immoral that they are irrational. The fact that they are the complete opposite of what the community perceives as moral or immoral makes them completely irrational. As Litton puts it very clearly: "Indeed, their actions in pursuit of excitement and pleasure, including their immoralities towards those ends, are not unintelligible to us in the same way that, say, a mere desire to place green books all over one's roof is unintelligible". Litton is not, however, the only one to ask questions about psychopaths' ability to behave rationally. For many years, Heidi Maibom has also been studying the impact of immorality on the lack of rationality of psychopaths' actions. According to her, in contrast, psychopaths know how to tell the difference between good and bad. Their immense problem lies in their complete inability to apply that knowledge: As opposed to the criminally insane, psychopaths exhibit knowledge of right and wrong. Nevertheless, their understanding is deviant and incomplete [17]. Maibom corroborates Litton's arguments by pointing out, once again, the difficulties psychopaths have adopting rational behaviour: Psychopathic individuals suffer from principled difficulties that non-psychopathic individuals do not. Compared to the normal population, they have impaired practical rationality. They have problems willing the necessary and sufficient means to their ends, making sure that specific intentions are internally coherent and consistent with the underlying intention, and determining whether foreseeable outcomes of their actions are compatible with their ultimate aim [18]. Thus, both authors come to the same conclusion: psychopaths do not have the ability to behave rationally. While the conclusion is the same, the two authors put forth different reasons explaining the irrationality. Litton places the source of psychopaths' irrationality in their immorality alone, insisting on their inability to follow moral rules set by the community. In contrast, Maibom thinks that psychopaths can tell right from wrong. The only difficulty lies in their inability to apply that knowledge rationally. Thus, in general, the two professors' positions are in the same direction: psychopaths do not have the ability to behave rationally. Psychopaths are unable to internalize the criminal norm and, more broadly, the values protected by society. Since moral judgments are based on emotional reactions that cannot take place without some rational reflection, it seems difficult to say that complete amorality allows an individual to behave rationally. This seems, in fact, to echo the position of Robert Hare, who strengthens our arguments by adding that the case of psychopaths is absolutely incomparable since they are unable to really comprehend what motivates other people, and they very often adopt inconsistent behaviour: One of our subjects, who scored high on the Psychopathy Checklist, said that while walking to party he decided to buy a case of beer, but realized that he had left his wallet at home six or seven blocks away. Not wanting to walk back, he picked up a heavy piece of wood and robbed the nearest gas station, seriously injuring the attendant [19]. That inconsistency is above all a manifestation of the deficiency of psychopaths' emotional systems. Psychopathic disorders indisputably show that the participation of emotion in the reasoning process is absolutely indispensable. While there used to be 
Journal of Forensic Science \& Criminology

discord regarding the roles of reason and emotions in the mechanisms at the origin of an individual's decision process, we have to observe that thanks to neuroscientific studies of psychopathy, this is no longer necessarily the case today because it has been proven that these two entities work together.

Thus, given all of these assertions, how should we analyse the case of psychopaths with regard to the Canadian insanity defence?

Under section 16 of the Canadian Criminal Code, the criminal responsibility of an individual cannot be attracted if that individual demonstrates that he or she was unable to assess the nature and quality of the action in question, or know whether the action was wrong [20]. Above all, since the clarifications brought by Bouchard-Lebrun, we know that Canadian criminal law excuses individuals who are unable to interact with their environment in a rational manner ${ }^{3}$.

It is from this point of view that criminal responsibility is assigned with regard to schizophrenic individuals, and people suffering from dementia or paranoid disorders. The defence has also been rejected in a number of cases with respect to psychopathic disorders [21]. Unlike the other disorders, psychopathy is not the direct product of a deficiency at the level of reason alone, but rather a deficiency that breaks the link between reason and emotions.

Yet, as we have seen through the detailed study of neuroscience, this link is fundamental because reason uses emotion to fine tune the decision process and thereby make it possible for an individual to behave rationally. Without emotion, reason cannot express itself fully, and, alone, remains insufficient to guarantee that the actions performed by the individual will be rational. Since an individual's actions are indisputably linked with his or her emotional faculties, it is evident that emotion is one of the most essential manifestations of human free will. All of these statements provide us with strong support in our reflection, and further weaken the perception that the justices of the Supreme Court have of psychopathy. Owing to the specific nature of the disorder, a psychopath could be considered irrational. Psychopathy is unique because it is the only disorder that reveals so clearly the role that emotion plays with respect to reason in the decision process and the capacity of any individual to behave rationally. While psychopaths know perfectly well what the terms good and bad mean, they are absolutely unable to apply that knowledge rationally. They do not have the ability to apply the knowledge of right and wrong rationally because they are unable to behave in compliance with all of the moral principles and values familiar to us. It is in this sense that Hervey Cleckley speaks of a "mask of sanity" when referring to the behaviour of psychopaths in society. That expression highlights the fact that psychopaths claim to feel the emotions that we feel every day, whereas they are unable to really understand them, and especially how to apply them [22]. Psychopaths thus have special status, for, although they can distinguish between right and wrong, they are absolutely unable to use that knowledge rationally. Psychopaths do not have the ability to behave rationally because psychopathic disorders undermine the very essence of the links between reason and emotions. Their thoughts and irrational actions do not flow from misunderstanding of what is good and bad, but indeed from an inability to apply that distinction to concrete situations. If an individual is unable to apply his or her knowledge of right and wrong rationally, to distinguish right from wrong in practical terms, and to adapt his or her actions in light of the moral principles promoted by our society, then we cannot decently consider that individual as criminally responsible. That individual is not criminally responsible because he or she does not have the level of rationality required to attract criminal responsibility. We therefore consider that, under section 16 of the Criminal Code, psychopathy, in particular at its most extreme stage, renders an individual unable to understand that the actions that he or she performs are deeply wrong in the sense of Bouchard-Lebrun.

\section{B) Psychopaths' lack of criminal responsibility justified by their irrationality: not such a good idea?}

The recent teachings of neuroscience have been very useful in thinking about psychopathy. Moreover, they could have a strong influence on possible application of the insanity defence to psychopathy. Nonetheless, the idea of incorporating psychopathy into the insanity defence needs to be tempered. In order to protect the public from the dangerousness of individuals who are often repeat offenders, the legislator and the judge seem inclined to analyse the social and societal consequences of possibly making psychopathy a disorder creating eligibility for the insanity defence. This pragmatism can be explained by the need to protect the public from the danger that psychopaths can entail owing to the disorder they suffer, and also because there is no viable treatment for psychopathy. In all democratic legal systems, fundamental principles govern life in society. The principles take different forms related to notions of justice and morality, or target social objectives pursued by the authorities. Those objectives include public safety [23] which is one of the most important issues with respect to smooth functioning of the state, as well as justice. The concept of public safety echoes the principles of criminal responsibility and the stakes involved in possibly making sufferers of psychopathic disorders eligible for the insanity defence [24]. In the context of our reflection on the very special case of the psychopath, the concept of public safety is indispensable, especially when we know that psychopaths have among the highest repeat offender rates [25]. Deeply disturbed by emotional and volitional disorders, a psychopath is an individual who tends to tirelessly repeat the same criminal actions. Public safety is impacted by this kind of individual, and both the legislator and the judge have to be able to provide appropriate legal and judicial responses [26]. Let us look at an example to illustrate this: in section 753 of the Canadian Criminal Code, the legislator has provided that an individual must be declared a dangerous offender if "the offence for which the

${ }^{3}$ R. v. Bouchard-Lebrun, 2011 CSC 58, [2011] 3 RCS 575, par. 49 : The criminal law relies on a presumption that every person is an autonomous and rational being whose acts and omissions can attract liability. This presumption is not absolute, however: it can be rebutted by proving that the accused did not at the material time have the level of autonomy or rationality required to attract criminal liability. Thus, criminal responsibility will not be imposed if the accused gives an excuse for his or her act that is accepted in our society, in which there is "a fundamental conviction that criminal responsibility is appropriate only where the actor is a discerning moral agent, capable of making choices between right and wrong 
offender has been convicted is a serious personal injury offence ... [there is] a pattern of repetitive behaviour by the offender, of which the offence for which he or she has been convicted forms a part, showing a failure to restrain his or her behaviour ... [or there is] a substantial degree of indifference on the part of the offender respecting the reasonably foreseeable consequences to other persons of his or her behaviour..." [27]. When we turn our attention to the principal criteria identified in section 753, we see that there is great similarity between the notion of a dangerous offender and the antisocial behaviour adopted by psychopaths. Thus, we can wonder whether this aspect of criminal law was not designed specifically for this type of individual. Indeed, a dangerous offender is unable to refrain from repeating his or her actions, and demonstrates marked indifference to the reasonably predictable consequences that his or her actions can have on others, which is also the case with individuals suffering from psychopathy. Is this a coincidence? We do not think so because we think that this legislation on dangerous offenders shows a desire to control psychopaths over the long term so as to meet public safety objectives. In substance, is it not specifically their inability to comply with social norms, and above all the determinism that afflicts them, which makes it impossible to align their situation with that of the insane, with respect to both criminal responsibility and sentencing?

The second element of the reflection underlying this principle of public safety is the fact that there is no viable treatment for psychopathy [28]. This information is fundamental from our point of view because the fact that there is no viable treatment and psychopaths' inability to adopt behaviour in compliance with social norms inevitably lead judges to classify them as dangerous offenders and to make them ineligible for the insanity defence. We consider that the determinism that they suffer makes it impossible for them to employ the insanity defence because the judge would be forced to place them in specific structures [29]. In Canadian criminal law, all decisions regarding an accused who is not criminally responsible must be taken in accordance with section 672.54 of the Criminal Code [30]. The procedure provided for in that section is, moreover, summarized in clear terms in Winko: "The task of the court or Review Board is to determine whether the evidence discloses a "significant" or real risk to the community should the NCR accused be released. If that risk exists, the NCR accused remains under supervision, either subject to conditions while living in the community or detained in a hospital. It does mean, though, that however difficult the task, the court or Review Board cannot avoid the responsibility of making that determination. Just as a jury is obliged to come to a conclusion on an accused's guilt or innocence, so is the court or Review Board required determining whether or not releasing the NCR accused would pose a "significant risk" to public safety. If, at the end the day, the court or Review Board cannot so conclude, the legal justification for confinement is absent and the NCR accused must be released..." [31].

In Swain, Lamer J. referred to the importance of therapeutic follow up of individuals declared not criminally responsible on account of mental disorder [32]. These two decisions thus highlight the importance of treatment in steps taken to rehabilitate individuals suffering from mental disorders in Canada. However, it is very complicated to provide psychopaths with care. Indeed, statistics show that psychopaths regularly fail when placed in a care facility because they resist treatment [33], and there is abundant research suggesting that they often manipulate those around them [34]. The present literature in Canada suggests also that psychopathy is a stable disorder for most individuals and many researchers remain sceptical about supposed changes in a personality disorder such as psychopathy with time [35]. For some scholars, current methods of treatment for psychopaths show no efficacy and many of them show detrimental effects [35].

Although psychopathic offenders are a challenging population to treat, some researchers consider that psychopathy is not untreatable. For them, these theories are largely based on outdated and poorly designed studies [36]. Moreover, this therapeutic nihilism on treating psychopathy [36] is inconsistent with important recent advances, which have been made in assessing psychopathy and recidivism risks. For Stephen Wong and Mark E. Olver for example, treatment programs in line with the model have been in operation, and the results of early outcome evaluations are encouraging [36]. Unfortunately, recents research from correctional service Canada seems to confirm that psychopaths tend to exploit unstructured programs, masking their resistance with verbal skills [37]. These results are major obstacles for correctional workers trying to provide appropriate intervention [37] and will certainly justify the severity of the judges.

\section{References}

1. Rc Bouchard-Lebrun (2011) CSC 58: 575.

2. Rationalité

3. Mongin P (2002) Le principe de rationnalité et l'unité des sciences sociales. Revue économique 53: 301-323.

4. Rationnel, Rationnelle

5. Rule J B (2002) Les leçons du choix rationnel Sociologie et societies 34; Gagne L (1997) Jon Elster et les limites de la rationalité: Choix rationnel et normes dans l'explication des comportements individuels M.A. thesis submitted to the Department of Political Science, Faculty of Graduate Studies at Laval University.

6. Cusson M (2015) Choix rationnel et pensée stratégique Dictionnaire de criminologie en ligne: Poupart J (2002) Choix rationnel et criminologie : limites et enjeux Sociologie et societies 34:133-145.

7. Morse SJ (2003) Diminished rationality, diminished responsibility Ohio State Journal of Criminal Law; Morse SJ (2000) Rationality and Responsibility Southern California Law Review 74; Ulen T.S (1999) Rational choice theory in law and economics Encyclopedia of law and economics 1:790-793.

8. Morse SJ (2003) Diminished rationality, diminished responsibility Ohio State Journal of Criminal Law.

9. Morse SJ (2002) Uncontrollable urges and irrational people. Faculty Scholarship. p. 648.

10. Blair JR (2003) Neurobiological basis of psychopathy. The British Journal of Psychiatry 182: 5-7 ; Raine A, Glenn A (2014) Psychopathy: An introduction to biological findings and their implications. NYU Press. 
11. Gazzaniga M (2005) Ethical brain. Dana Press p.101.

12. Damasio AR (1994) Emotion, reason and the human brain. Avon Books.

13. Damasio AR (1994) Emotion, reason and the human brain. Avon Books. p.7-10.

14. Damasio AR (1994) Emotion, reason and the human brain. Avon Books p.173.

15. Cleckley H (2003) The mask of sanity: An attempt to clarify some issues about the so called psychopathic personality. American Journal of Psychiatry 113 : 92.

16. Litton P (2008) Responsibility status of the psychopath: On moral reasoning and rational self-governance. Rutgers Law Journal $39: 375$.

17. Maibom H Moral (2005) Unreason: The case of psychopathy. Mind \& Language 20: 241.

18. Maibom H Moral (2005) Moral unreason: The case of psychopathy. Mind \& Language 20: 244-245.

19. Hare R (1993) Without conscience: The disturbing world of the psychopaths among Us. New-York, Guilford Press $125: 40-41$.

20. Code criminel, LRC (1985), C-46, art 16.

21. Kjeldsen v. La Reine, [1981] 2 RCS 617 ; R. v. Simpson, (1977) 35 C.C.C. (2d) 337.

22. Cleckley H (2003) The mask of sanity: An attempt to clarify some issues about the so called psychopathic personality.

23. Divito v.Canada (Sécurité publique et Protection civile), 2013 CSC 47, [2013] 3 R.C.S. 157.

24. Petrosino AJ, Petrosino C (1999) The public safety of Megan's law in Massachusetts: An assessment from a sample of criminal sexual psychopaths. Crime and Delinquency 45.

25. Barbaree HE (2005) Psychopathy, treatment behaviour and recidivism: an extended follow-up of Seto and barbaree. Journal of interpersonal violence 20: 111531.

26. Ortega RJ, Fitch L (2000) Law and the confinement of psychopaths behavioral. Sciences and the law 18.

27. Code criminel, LRC (1985) C-46, art.753

28. Hart SD (1998) The role of psychopathy in assessing risk for violence: conceptual and methodological issues. Legal and criminological psychology 3: 121-37.

29. Levy K (2011) Dangerous psychopaths: Criminally responsible but not morally responsible, subject to criminal punishmentaAnd to preventive detention. San Diego law review 48.

30. Code criminel, LRC 1985, C-46, art 672.54

31. Winko v. British Columbia (Forensic Psychiatric Institute), [1999] 2 SCR 625.

32. Rv. Swain [1991] 1 R.C.S. 933.

33. Pham TH, Cotte G (2000) Psychopathie : théorie et recherche. Presse universitaire du septentrion.

34. Pham TH, Saloppe X, Leistedt S (2012) La manipulation et le mensonge pathologique de la psychopathe comme défi majeur pour la recherche de la vérité judiciaire. Annales Médico-Psychologiques, 170: 141-142.

35. Shaw J and Porter S (2012) Forever a psychopath? Psychopathy and the Criminal Career Trajectory in Helinä Häkkänen-Nyholm and Jan-Olof Nyholm, Psychopathy and Law: A Practitioner's Guide p. 204.

36. Wong SCP, Olver ME (2015) Risk reduction treatment of psychopathy and applications to mentally disordered offenders. CNS Spectr. 20: 303-310.

37. FORUM on Corrections Research 